\section{Effects of new social movements on different countries: Cases from Tunusia, Egypt, Turkiye and France}

\section{Yeni toplumsal hareketlerin farklı ülkeler üzerindeki etkileri: Tunus, Misir, Türkiye ve Fransa'dan örnekler}

\author{
Selim Çapar ${ }^{1}$ \\ Mehmet Koca ${ }^{2}$
}

\begin{abstract}
Social movements, that have been conceptualized as new with serious transformations in their content and implementation since the 1960s, which have the potential to influence current political/social debates or decisions, has entered social life in a way that no one can easily ignore in terms of their effects. The increasing visibility and impact of social movements, especially since the 2000 s, differ significantly depending on whether countries have established democracy or not. The social movements that are widespread throughout the country do not cause a radical change in the country's administration in countries with a built-in democracy culture and consciousness, like Turkey and France, through the examples of countries studied in this work. Because in these countries, there is a system in which demands could be reflected through democratic elections. On the other hand, in countries where democracy culture is not fully established, like Egypt and Tunisia, social movements are thought to have a high capacity
\end{abstract}

\section{Özet}

Güncel politik/toplumsal tartışmalara ya da kararlara yön vererek onları etkileme potansiyeline sahip olan ve 1960'lı y1llardan itibaren içeriğindeki ve uygulanış şeklindeki ciddi dönüşümler ile yeni olarak kavramsallaştırılan toplumsal hareketler etkileri itibariyle artık kimsenin kolayca göz ardı edemeyeceği bir şekilde toplumsal hayata girmiştir. Özellikle 2000'li yıllardan itibaren toplumsal hareketlerin artan görünürlüğü ve etkisi ise sonuçları itibariyle ülkelerin yerleşik bir demokrasiye sahip olup olmamasina göre önemli derecede farklilik arz etmektedir.

Ülke genelinde yayginlaşan toplumsal hareketler, bu çalşmada incelenen ülke örnekleri üzerinden yerleşik bir demokrasi kültürüne ve bilincine sahip olan ülkelerde Türkiye ve Fransa gibi- ülke yönetiminde köklü bir değişikliğe sebep olmamaktadır. Çünkü bu ülkelerde demokratik seçimler yoluyla taleplerin yansıyacağ1 bir sistem bulunmaktadır. Öte yandan, demokrasi kültürü tam olarak yerleşmemiş ülkelerde -Misır ve Tunus gibi-

\footnotetext{
1 Associate Prof., Head of GAMER/AREM, Ministry of Interior, caparselim@gmail.com, (iD) Orcid ID: 0000-0001-5597-584X

2 Expert of Province Planning, AREM, Ministry of Interior, mehmetarem@gmail.com, (iD) Orcid ID: $\underline{0000-0002-3500-519 X}$
} 
Çapar, S., \& Koca, M. (2020). Yeni toplumsal hareketlerin farklı ülkeler üzerindeki etkileri: Tunus, Mısır, Türkiye ve Fransa'dan örnekler. Journal of Human Sciences, 17(2), 642-658. doi:10.14687/jhs.v17i2.5986

to cause radical changes in the administration with the influence of different actors.

Keywords: Social Movements; Psychology of Mass; Communication; Democracy; Protest.

(Extended English summary is at the end of this document) toplumsal hareketlerin farklı aktörlerin de etkisiyle yönetimde köklü değişikliklere yol açma kapasitesinin yüksek olduğu düşünülmektedir.

Anahtar Kelimeler: Toplumsal Hareketler; Kitle Psikolojisi; İletişim; Demokrasi; Protesto.

\section{GİRIŞ}

Toplumsal hareketlerin tarihi, insanlık tarihi kadar eskilere götürülebilmektedir. Ancak, bu alanda yaşanan dönüşüm ile birlikte değerlendirildiğinde politik/toplumsal tartışmalara ya da karar alma süreçlerine olan etkisi, 20. yüzyılln ikinci yarısından itibaren özellikle de 21. yüzyıl ile birlikte gözle görülür bir şekilde değişime uğramıştır. Bu bağlamda, "yeni toplumsal hareketler" kavramsallaştırması ortaya çıkmıştır. Yeni toplumsal hareketler ülkelerdeki siyasal sistemin özelliklerine göre farklı ülkelerde farklı etkiler oluşturma kapasitesini bünyelerinde barındırmaktadır.

Günümüzün dünyasında küçük bir coğrafyada ortaya çıkan ekonomik veya sosyal bir sorun, iletişim kapasitesinin etkililiği sayesinde çok hızlı bir şekilde farklı coğrafyalara yayılabilmektedir. Böylece, başlangıçtaki sorun alanlarından referans alarak farklı alanlara sirayet edebilmekte ve gelişim süreçleri içerisinde, hızlı savrulmalar yaşayarak siyasi değişiklik taleplerine kadar dönüşebilmektedir.

Bu çalışmanın konusu toplumsal hareketlerdir. Amacı yeni toplumsal hareketlerin demokrasi kültürü ve bilincinin yerleşikliği esasında farklı ülkeler üzerindeki etkilerini incelemektir. Bu amaç doğrultusunda, seçilmiş ülkeler üzerinde 2000'li yıllarda ortaya çıan yeni toplumsal hareketlerin etkileri karşılaştırmalı olarak değerlendirilecektir. Bu bağlamda, öncelikle demokrasi kavramı ele alınacak, toplumsal hareketler ve bunların değişim seyri analiz edilecektir. Türkiye, Fransa, Misır ve Tunus'ta yaşanan toplumsal hareketler, ortaya çıkışları, gelişim süreçleri ve etkileri olarak değerlendirmeye tabi tutulacaktır.

\subsection{Demokrasi}

\section{KAVRAMSAL ÇERÇEVE}

Demokrasi kavramı, ortaya çıktığ1 andan itibaren ne olduğu veya olmadığ hususunda üzerinde sürekli tartışlan bir kavram olagelmiştir (Güçyetmez, 2017, 481). Kavram etimolojik olarak "halk iktidarı" anlamına gelmekle birlikte, günümüzün modern toplumlarında çok farklı anlamlar ve muhteviyatlar kazanmış bununla birlikte birbirinden farklı uygulamaları kavramsallaştırmada kullanılan bir olgu halini almıştır. Bu farklılıklar da doğal olarak 'demokrasi' kavramının genel bir tanımının verilmesini zorlaştırmışıı (Ural, 1999, 451).

Demokrasi tanımlamalarında, genellikle çoğunluğun egemenliği öne çıkmakla birlikte, kavram Sokratesçi bir diyalogda ya da tartışmadaki gibi sıkıştırllırsa çoğunluğun rızası şeklinde bir değişime uğramıştır (Crick, 2002, 17).

Demokrasi en temel anlamı itibariyle "halkın kendi kendini yönetme biçimi" olarak betimlendirilmektedir. Latince kökenleri bakımından halk manasına gelen "demos" ile "iktidar" manasına gelen kratos sözcüklerinden oluşmaktadır. Bu kapsamda demokrasi egemenliğin vatandaşların uhdesinde olmasını ön plana çıkartan kavramdır. Abraham Lincoln yapmış olduğu bir konuşmasında demokrasiyi "halkın, halk tarafindan, halk için yönetimi”" olarak kavramsallaştırmıştır. Tunç'un aktarımları ile Atatürk ise demokrasiyi tanımlarken "Demokrasi prensibi, hakimiyete [istimal] $^{3}$ eden vasita ne olursa olsun esas olarak milletin hakimiyete sahip olmasını ve sahip kalmasını

\footnotetext{
3 Atatürk'ün bu sözü Afet İnan (2010: 27) tarafindan kaleme alınan "Medeni Bilgiler” kitabında yer almaktadır. Alıntrlama yapılırken kullanma anlamındaki "istimal” kelimesi, sehven "istismak" olarak geçirilmiş ve sonraki alıntılar da, ilk kaynak yerine "alıntı" tercih edilince, bu sözde hatalı kelime kullanımı yanlışının zincirleme biçimde devam ettiği görülmektedir.
} 
Çapar, S., \& Koca, M. (2020). Yeni toplumsal hareketlerin farklı ülkeler üzerindeki etkileri: Tunus, Mısır, Türkiye ve Fransa'dan örnekler. Journal of Human Sciences, 17(2), 642-658. doi:10.14687/jhs.v17i2.5986

icap ettirir", "Demokrasi esasına müstenit hükümetlerde, hakimiyet halka, halkın ekseriyetine aittir. Demokrasi prensibi, hakimiyetin millete ait olduğunu, başka yerde olamayacağını iltizam eder. Bu suretle, demokrasi prensibi, siyasi kuvvetin, hakimiyetin menşeine ve meşruiyetine temas etmektedir" diyerek kavramsal çerçevesini çizmiştir (Tunç, 2008, 1115).

Demokrasi kavramının tarihsel süreç içerisinde kullanıldığı görülmektedir. Demokrasi ilk olarak Yunanlılarda kullanılmıştır. Burada Platon'un kavrama saldırısında ve Aristotoles'in nitelikli savunmasında yer almaktadır. Kavramın ikinci kullanımı Roma Cumhuriyet'inde Machiavelli'nin Söylevler'inde, 17. yüzyıl İngiliz ve Hollandalı cumhuriyetçiler ile ilk Amerikan cumhuriyetinde kullanılmış, üçüncü kullanımı Fransız devriminin retoriği ve olayları esnasında Rosseau'nun yazılarında ortaya çıkmış ve dördüncü kullanımı Amerikan anayasası ile 19. yüzyıl Avrupa’sının yeni anayasalarının çoğunluğunda, İkinci Dünya Savaşı sonrasında hazırlanan Batı Almanya ve Japon anayasaları ile Mill ve Tocqueville'in yazılarında görülmüştür (Crick, 2002, 21-23).

Tarihin akışı içerisinde birikerek oluşan deneyimlerden hareketle bugün kavrama ilişkin daha geniş kapsamlı betimlemeler ortaya çıkmış ve kavram Tunç'un da aktarımları ile "En üst iktidarın halkta bulunduğu ve halkın belli aralıklarla tanınan özgür seçimlerde, temsilcilerini seçtiği, temsil ve devredilmiş otorite yoluyla halk tarafından dolaylı olarak kullanılan hükümet biçimine imkan veren siyasi sistem" (Tunç, 2008, 1115) biçiminde tanımlanmışıır.

Kavrama ilişkin bir çok tanımın yapılması beraberinde demokrasi türlerinin çeşitliliğini de getirmiştir. Bu kapsamda literatüre bakıldığında en genel manada demokrasinin çeşitleri doğrudan, yar1 doğrudan, temsili ve liberal demokrasi olarak sayılmakla birlikte (Aktaş, 2015, 92-94) Tunç bunlara ek olarak temelindeki amaca göre demokrasi türlerini klasik, çoğunlukçu, marksist, plebisitçi, radikal, siber, düşük yoğunluklu, militant, uzlaşmacı, delegasyoncu, Westminister modeli, oydaşmac1, müzakereci demokrasi olarak sıralamıştır (Tunç, 2008, 1117-1124).

Literatürde baskın olarak yer alan demokrasi türlerinin tanımlarına kısaca bakılacak olursa "Halkın doğrudan doğruya egemenlik hakkını kullanarak aldığı politik kararların uygulandığ1 doğrudan demokrasi, egemenliğin paylaşımının halk ile temsilcilerinin arasında yapıldığı yarı doğrudan demokrasi, egemenliğin vatandaşların düzenli bir şekilde belirli aralıklar için seçtiği temsilcileri vasıtasıyla ile yerine getirildiği temsili demokrasi, anayasa ile devletin güç ve yetkilerinin çerçevelendiği ve bireysel hak ve özgürlüklerin garanti altına alındığı bir yönetim şekli olan liberal demokrasi” olarak tanımlandığı görülmektedir (Aktaş, 2015, 92-94).

\subsection{Toplumsal Hareketlere Teorik Yaklaşımlar}

Toplumsal hareketler literatürü bağlamında, her toplumsal hareketin diğerlerinden çok farklı nitelikler taşıması nedeniyle bu olgunun tek ve her hareketi kapsayan bir kavramsallaştırılmasının yapılmasının oldukça zor olduğu görülmektedir (Soysal, 2018, 63). Bununla birlikte Demiroğlu (2014, 134), toplumsal hareketleri, "seçkinlere, otoriteye, diğer gruplara ya da sosyo-kültürel verilere karşı, bu sayılan unsurlar ile devam eden bir etkileşim içinde, aynı hedefleri bulunan ve işbirliği içinde hareket eden bireyler tarafindan geliştirilen ortak eylemler" olarak tanımlamıştır.

Toplumsal hareketler, toplumsal tabakalar arasında varolagelen anlaşmazliklardan türeyen ve kolektif eylem şeklinde ortaya çıan hareketler olarak tanımlanabilir (Collas, 2002, 69). Giddens (2000, 540-541) 'e göre toplumsal hareketler "yerleşik alan haricindeki ortak eylemler yoluyla ortak bir çıkara veyahut hedefe ulaşmayı sağlayabilmek için girişilen kolektif bir çaba" olarak görülmektedir. Dayanışmadan kaynaklanan dinamizmle ilerleyen toplumsal hareketler, çatışma yöntemiyle itiraz ettiği sistemin zorlamalarına kolektif biçimde direnişi ifade etmektedir (Işık, 2016, 18).

Toplumsal hareketlere ilişkin düşüncelerin, bu hareketler kadar eskiye uzandığ ifade edilebilir. Bizim anlamlandırdığımız şekliyle modern sosyal bilimlerin evrimleşmeye başladığı 19. yüzyıldan itibaren bu alana yönelik daha sistemli yaklaşımlar ve analizler kendini göstermeye başlamıstır (Çetinkaya, 2018, 27).

Fransız Devriminden günümüze gelen süreçte iki yüzyıldan fazla bir süredir tarih sahnesinde yer alan toplumsal hareketler kavramı (Dirlik, 2018, 75) Saint Simon tarafindan ilk defa 18. Yüzyıl Fransa's1 ve diğer ülkelerdeki yönetimlere karşı ilk kez meydana çıkan politik güçlerin ortaya çıkardığ1 kolektif tarzdaki eylemleri kavramlaştırmak için kullanılmıştır (Mermer, 2016, 12). 
Çapar, S., \& Koca, M. (2020). Yeni toplumsal hareketlerin farklı ülkeler üzerindeki etkileri: Tunus, Mısır, Türkiye ve Fransa'dan örnekler. Journal of Human Sciences, 17(2), 642-658. doi:10.14687/jhs.v17i2.5986

Modernite ile birlikte kalabalıklar yaklaşımı ortaya çıkmıştır. Bu yaklaşımın tipik bir temsilcisi Gustave Le Bon (1977) olmuştur. Le Bon'a göre bu tarz hareketler daha ziyade irrasyonel bir durumu ifade etmektedir; bu yüzden kalabalıkların eylemleri de bir çılgılık anı olarak betimlenir (Çetinkaya, 2018, 30). Le Bon (1997) kitle ve birey arasında ortaya koyduğu ilişkiye göre, bireyin kitleye girdiğinde kimliksizleşeceğini, kitlelerin bireylerden bağımsız ruhları olduğunu, dolayısıyla kitlenin kendisini meydana getiren bireylerin kişiliklerinden bağımsız biçimde belirli bazı özellikleri olacağını ifade etmiştir.

İkinci Dünya Savaşı sonrası dönemde dikkatleri üzerine çeken Kitle Toplumu Teorisi'ne göre ise başkaldırı ve toplumsal hareketler, modernleşmenin getirdiği faydaların ulaşamadığı kitlelere ulaştı̆̆ında sona erecek gelişmelerdir (Çetinkaya, 2018, 31). Bu teorinin başta gelen düşünürlerinden biri Smelser (1962)'dir. Bu yaklaşım, İkinci Dünya Savaşı sonrası dönemdeki iyimser kalkınmacı bir felsefeye dayanmaktadır (Çetinkaya, 2018, 31). Bu yaklaşıma göre, modernleşmeye yönelik tepkilerin geçici bir nitelik taşıdığı, tepki gösteren dezavantajlı grupların modernleşmenin getirdiği nimetlerden yararlanmaya başladıklarında moderniteye entegre olacakları beklenmektedir (Aslan, 2016: 5).

Toplumsal hareketleri değişmez inançların ve sürü psikolojisinin bir yansıması olarak algılayan düşünsel yapının aksine Rasyonel Ekol, bireylerin rasyonel eylemlerinin bir dişa-vurumu olarak açıllama eğilimi içine girmiştir (Çetinkaya, 2018, 31). Bu yaklaşımda Olson (1965) liberal iktisat düşüncesinin varsayımlarını toplumsal hareketlere uyarlamıştır. İnsanların rasyonel ve kişisel çıkarlarını düşünen bireyler olduğunu öne sürmektedir. Dolayısıla, bireyin çıkarı peşinde koştuğunu, ortak ve grup çıkarı için harekete geçmesini, ancak zorlama ve özendiricilerin sağlayabileceğini ifade etmektedir (Olson, 2002, 2).

1960'lı yllar ile birlikte toplumsal hareketlerin yükselmeye başlaması, akademik çalışmalar alanında da etkisini göstermiş ve günümüzde önemli yeri olan iki okulu ortaya çıkarmıştır. Bunlardan biri, daha çok ABD'de etkili olan Kaynak Mobilizasyonu Teorisi; diğeri ise Avrupa'da etki eden Yeni Toplumsal Hareketler yaklaşımıdır (Çetinkaya, 2018, 33).

Kaynak Hareketliliği Teorisi'nin Olson'un çalışmaları ile bağlantısı bulunmaktadır. Bu teorinin temel düşüncelerini oluşturan McCarty ve Zald (1977), protesto faaliyetinin toplumsal hareket örgütleri üzerine odaklanmıştır. Bu örgütler protesto faaliyetinin diğer bir bileşenidir (Çetinkaya, 2018, 34). Kaynak Hareketliliği Teorisi, odak noktasını kitle psikolojisinden uzaklaştırmış ve hareketin ortaya çıkması ile gelişmesinde önem taşıyan politik, sosyolojik ve ekonomik kaynaklar olarak diğer etkenlere yoğunlaşmaktadır (Soysal, 2018, 68). Bu teoriye göre bir hareketin ortaya çıkması için, ekonomik kaynaklar başta olmak üzere, belli başlı kaynakların seferber edilmesi gerekmektedir.

Kaynak Hareketliliği Teorisi ile birlikte ele alınan Politik Süreçler (Olanaklar) Kuramı da vardır. Bu teori, toplumsal hareketleri belli bir çerçeve içinde ele alma gayretinin ifadesi olarak ortaya çıkmıştır. Bu teori bağlamında görüş oluşturanlar, toplumsal hareketlerin daha ziyade içinde var oldukları politik sistem ve o sisteme karşı olan fiillerini kapsayan ilişkiler ağına odaklanmışlardır (Çetinkaya, 2018, 35). Bu yaklaşımın yaygın görülen biçimi, toplumsal hareketler ve devlet arasındaki ilişkilere yoğunlaşma olarak ortaya çıkmıştır. Bu bağlamda, toplumsal hareketler baskının azaltılması, ekonomik ve politik elitler arasında belirecek bir çatışma sayesinde ortaya çıkan imkanları kullanarak büyürler (Çetinkaya, 2018, 35).

Kaynak Hareketliliği ve Politik Olanaklar teorileri çerçevesinde araştırma yapan araştırmacılar, gün geçtikçe analizlerine daha farklı unsurlar katarak, bu yaklaşımların zenginleşmesine katkı vermişlerdir. Bu kapsamda, 1980'li yıllardan sonra Kültürel Çalışmalar'ın alanyazını üzerinde önemli etkileri ortaya çıkmıştır (Çetinkaya, 2018, 35-36). Kültür konusunda, çerçeveleme ve kolektif kimlik konuları öne çıkmaya başlamıştır. Duyguların toplumsal hareketlere katılanlar üzerindeki etkisi konusu da gündeme gelmeye başlamıştır (Aminzade ve McAdam, 2002). Öte yandan, 1980'li yılların başından itibaren sosyal psikoloji yeniden güçlü biçimde çalışmalara dahil edilmiştir (Çetinkaya, 2018, 37; Aslan, 2016). Bu süreçte duygular ile birlikte fikir, düşünce ve ideolojilerin de toplumsal hareketlere olan etkisi yeniden ele alınmıştır (Çetinkaya, 2018, 37-38). Bu gelişmelerle birlikte, bu yaklaşımın en önemli vurgusu olan toplumsal hareket örgütlerinin yerini almaya başlamış olan toplumsal ağ yaklaşımı bile, bu teorinin içinde kendine yer bulmuştur (Çetinkaya, 2018, 40). Charles 
Çapar, S., \& Koca, M. (2020). Yeni toplumsal hareketlerin farklı ülkeler üzerindeki etkileri: Tunus, Mısır, Türkiye ve Fransa'dan örnekler. Journal of Human Sciences, 17(2), 642-658. doi:10.14687/jhs.v17i2.5986

Tilly, Sidney Tarrow ve Doug McAdam (2001) bu teorinin geliştirilmesi konusunda önemli katk1 vermiştir.

Toplumsal hareketler, anlık eylemler gibi görünüm verseler de, tarihsel özellikleri vardır. Tilly $(2008,24)$ 'e göre, toplumsal hareketler tarihsel bağlam içinde tarihsel gelişimlerinin izlenmesiyle anlaşılabilir.

Diğer yandan, Yeni Toplumsal Hareketler literatürü ile Kaynak Hareketliliği literatürü yeni kavramları bünyelerine dahil etme sürecinde birbirlerine yakınlaşmışlardır. Yeni Toplumsal Hareketler yaklaşımı da var olan hareketleri alısıılmış siyasetin bir parçası olarak görmektedir (Çetinkaya, 2018, 43). Böylece, aslında her iki yaklaşım açısından da, toplumsal hareketlerin yeni zamanların toplum biçimi içindeki bir unsur olarak değerlendirdikleri anlaşılmaktadır.

Başına "Yeni" ibaresini alan yaklaşıma göre, eski toplumsal hareketlerin, toplumsal değişim sebebiyle temel özelliklerinin altı boşalmıs durumdadır. Yeni toplumsal hareketlerin oluşmasını sağlayan "yeni" toplum modelidir (Aslan, 2016, 143). Bu nedenle, daha çok belli iktisadi hedeflere yönelen, devrimi veya yönetimin değişimini hedefleyen toplumsal hareketlerin varlıkları artık görülmemektedir.

Yeni toplumsal hareketlerin, otonomi ve kimlik üzerinde durmaları önemli özelliklerindendir. Bu hareketler, iktidar mücadelesinden ziyade savunma nitelikli hareketlerdir (Çetinkaya, 2018, 46). Yeni toplumsal hareketlerin ortaya çıkmasında belirleyici unsur, ortaya çıkan yeni çelişki ve eşitsizliklerin yarattığı hayal kırıklıklarıdır (Aslan, 2016, 143). Bu hareketler, demokrasi ve sivil toplum üzerine inşa edilmiş ve tüm muhalif hareketleri bir çatı altında toplama potansiyeli taşımaktadır (Aslan, 2016, 144-145).

Yeni toplumsal hareketler, sosyoekonomik ihtiyaçlardan daha çok kültürel, varoluşsal veya hayat biçimleri ile ilgili konu başlıklarına karşı daha duyarlılık göstermektedir. Bu bağlamda, amaçları, çoğunlukla iktidarı ele geçirmek ya da karşı çıkmaktan ziyade, devlete karşı özerk alanlar oluşturmak ve devletin etkisine karşı özel toplumculuk biçimlerinin bağımsızlığı konusunda 1srarlı olmaktır (Lelandais, 2009, 68-69). Yeni toplumsal hareketler, mücadelenin merkezine iktidar1 yerleştirmekten ziyade, toplumsal hayatta daha özerk alanlar yaratılmasına ilişkin konulara odaklanmaktadır (Işık, 2016, 35).

\subsection{Toplumsal Hareketler ve İletişim}

Tarihsel süreç içerisinde teknoloji başta olmak üzere hemen hemen her alanda yaşanan değişim ve dönüşümler, ülkelerin bütün organizasyonlarını bir şekilde etkilemiş, bu şekilde ortaya çıkan değişimlerde toplumların içinde yaşadıkları dünyayı anlamlandırma biçimleri üzerinde derin değişiklikler ortaya çıkarmıştır. Bu sürecin odak noktasında ise beşeri faktörler kadar, teknolojik gelişim ve dönüşümün hayatımıza sunduğu yeni medya etkili bir ortam olarak yerini almıştır (Çayc1, 2015, 27).

Toplumsal hareketler için etkileşim, etkileşim için ise iletişim temel bir unsurdur. Bir toplumsal hareketin ortaya çıkması ve etki etmesi açısından gerek harekete katılanlar arasında, gerekse hareket ile toplum arasında sürekli iletişime ihtiyaç bulunmaktadır. İletişimin en önemli görevi, toplumsal hareketlere katılım sağlayanlar ve toplum için ortak kıymetlerin ortaya çıkmasına katkı sağlamasıdır (Işı1, 2016, 4).

Toplumsal hareket bakış açısından, toplumun medya ile bilgilendirilmesi önem taşımaktadır. Bu sebeple toplumsal hareketlerin amaçlarını ve haklılıklarını geniş kitlelere duyurabilmek için medya ile kurulan ilişkinin kilit bir rolü bulunmaktadır. Medya ve toplumla kurulan iletişim ağı, hem toplumsal hareketlerin topluma ulaşmasina aracilık etmekte, hem de toplumun toplumsal hareketleri etkilemesine imkan tanımaktadır (Işs1k, 2016, 4).

Medya, olayların nasıl algilandığı konusunda önemli bir güce ve etkileme yeteneğini haizdir (Philips ve Szagala, 2007, 40). Medya ile ilişkiye girildiğinde ülkenin tarihsel durumu, ideolojik geleneği ve diğer şartlar altında gruplar ile toplum arasında etkileşimi içeren bir bilgi alısverişi başlamış olacaktır (Kılıç, 2009, 104).

Toplumsal hareketlerin, medya ve toplumla iletişim kurmasına imkan veren yönetim sistemine sahip ülkelerde daha kolay örgütlenebileceği öngörülebilir. Ülkelerin demokrasi geleneği, 
Çapar, S., \& Koca, M. (2020). Yeni toplumsal hareketlerin farklı ülkeler üzerindeki etkileri: Tunus, Mısır, Türkiye ve Fransa'dan örnekler. Journal of Human Sciences, 17(2), 642-658. doi:10.14687/jhs.v17i2.5986

kültürü, deneyimi ve düzeyinin, toplumsal hareketlerin başlaması, seyri ve sonuçlanması üzerinde önemli etkiler ve farkllikklar oluşturabileceği ifade edilebilir.

Geleneksel yazllı ve görsel medya yanı sıra bilgi toplumu ile birlikte alternatif medya ortamı olarak internet, toplumsal bir hareketin kamuoyuna yansitilmasinda ve hareketin kitleselleştirilmesinde stratejik bir araç niteliği taşımaktadır (Işık, 2016, 2016: vi). Tilly $(2008,137)$ 'e göre radyo, TV, e-posta, anket ve kampanyaların oldukça geniş bir ölçekte tanıtım ve yaygınlaşmasını sağlayan internet ağının dünya çapında olması, toplumsal hareket etkinlikleri ve gösterilerine yeni boyutlar kazandırmaktadır. Teknolojik gelişmeyle koşut biçimde artış gösteren ağ bağlantıllı iletişim kanalları, toplumsal hareketlerin başlamasında, varlığını ve etkililiğini sürdürmesinde vazgeçilmez unsur olarak yerlerini almıştır (Işık, 2016, 9).

Yeni toplumsal hareketlerin ortaya çıkması ve gelişim evresiyle birlikte, küreselleşmenin de bu sürece katkısı göz önüne alındığında çok farklı yerlerde benzer sorun alanlarını toplumsal hayata aktaran çevrelerin artması, küresel düzlemde işbirliği içinde ve eşanlı olarak hareket etmesi, sorunlar için ulusal sınırları aşan çözüm ihtiyaçlarını ortaya çıkarmaların mümkün hale getirmiştir. Bu sürecin ortaya çıkmasında ise küreselleşme ile birlikte 1990'lı yılların da sonrasında internetin kitleselleşmesi ve alternatif bir iletişim aracı haline gelmesi önemli bir role sahiptir (Çayc1, 2015, 37).

Alternatif medya, anonimleşmeye başlayan ve halihazırdaki güçlerden ayrı olarak hareket edebilen, yeni iletişim teknolojileri ve özellikle internet medyası olarak tanımlanmaktadır (Işık, 2016, 6). Mobil tabanlı sosyal medya üzerinden, herhangi bir sınırlamaya tabi olmadan yazılı, görsel ve ses dosyalarının paylaşılması sağlanmaktadır. İnternet ortamındaki sosyal ağlarda bilgi, haber, yorum, resim, video, film gibi materyaller yüklenerek diğer kullanıcılar ile etkileşime geçilebilmektedir. $\mathrm{Bu}$ uygulamalar üzerinden, artan beğeniler aracıllı̆ı ile giderek daha çok artan bir etkileşim düzlemi ortaya çıkmaktadır (Komito ve Bates, 2009, 233). Bu gelişmeler doğrultusunda, haber tüketicilerinin çoğunluğunun alternatif medya üzerinden ve sosyal medya kullanıcılarının neredeyse yarısının sosyal medya üzerinden haberlere ulaştıklarına işaret edilmektedir (Işı1k, 2016, 10).

Sosyal medya sayesinde, kendi hayatlarını istedikleri şekilde ifade etmek isteyen bireylerin diğer bireyler ile birlikte kurduğu bağlar hızla çoğalmış ve sosyal medya son derece dağınık ve bireysel hareket eden bu kitlelerin fiziksel biçimde toplanmasını kolaylaştırarak bir araya gelme bilincinin oluşturulmasina katkıda bulunmuştur (Dolgun ve Sütlüoğlu, 2014, 10).

Bu bağlamda, yeni medya/sosyal medya sonrası yeni toplumsal hareketler çerçevesinde bütün taraflarıyla yaşanılan bu yeni sürecin sui generis özelliği olarak yeni bir birey tipinin meydana geldiği görülmüsstür (Babacan, 2015, 303).

\section{TOPLUMSAL HAREKETLERDE ÜLKE ÖRNEKLERİ}

Toplumsal hareketler, insanlık tarihi boyunca toplumları kısmen ya da bir bütün olarak kurumları, yargıları ve değerleri ile dönüştüren ve bunun neticesinde de yeni değer ve hedefler üreten hareketler olmuşlardır. Teknolojinin gelişimi ile birlikte üretim ve sermaye yapılarının dönüşümü ve iletişimin ağının tüm dünyaya yayılımı beraberinde toplumsal hareketlerin odağına yerleştirdiği konuları ve amaçları da değiştirmiştir (Çayc1, 2015, 41).

Enformasyon, risk, gözetim ve ağ toplumu olarak kavramsallaştırllan 21. yüzyllın postmodern dönemlerinde gençlerin başını çektiği toplumsal hareketler (Bayhan, 2014, 24) artık odak noktasına kimlik, demokrasi, terörizm veya daha iyi bir yaşamı vaadeden ekonomi merkezli konuları ele almaya başlamıştır (Çayc1, 2015, 39).

Çalışmanın bu bölümünde ülke örnekleri üzerinden toplumsal hareketlere ve sonuçlarına ilişkin açıklamalar yapılacak olup, bu kapsamda Tunus, Misır, Fransa ve Türkiye'deki toplumsal hareketlere değinilecektir.

\subsection{Tunus}

Tunus, 2011 yllında bölge ülkelerinde bir dizi kritik değişime yol açan ve yeni olarak kavramsallaştırılabilen toplumsal hareketlerin başladığı ülke olmuştur. Olayların başladığı 2011 yılında nüfusu 11 milyon civarında olan Tunus'un en önemli gelir kaynağı tarım olup, gelişen bir turizm 
Çapar, S., \& Koca, M. (2020). Yeni toplumsal hareketlerin farklı ülkeler üzerindeki etkileri: Tunus, Mısır, Türkiye ve Fransa'dan örnekler. Journal of Human Sciences, 17(2), 642-658. doi:10.14687/jhs.v17i2.5986

sektörüne de sahiptir. Sanayi sektörünün zayıf olduğu ülkede 2011 yllı itibariyle kişi başı GSYH 8 bin ABD doları civarındadır (Taştan, 2018, 119-120).

Tunus'ta sokak isyanı ya da halk hareketleri, yeni toplumsal hareketlerin gerçekleştirdiği ilk devrimi oluşturmaktadır. Bu sokak hareketleri yönetimin muhalefeti kontrol altına alamadığını ve denetleyemediğini göstererek “iktidar her yerdedir” mantığını da çürütmüştür (T1ğlı, 2011, 11).

Yaşanan olaylar Tunus başta olmak üzere Ortadoğu ve Kuzey Afrika’da yeni bir dönemin başlangıcına da referans olmuştur. Tunus'ta yaşanan halk isyanı sırasında toplam 219 kişinin yaşamını kaybetmesine karşın, alevlenen toplumsal hareketler kısa sürede tüm bölgede yerleşik yönetimlere karşı yeni başkaldırıların başlamasına (Ayhan, 2012, 59) ve benzer sosyoekonomik ve siyasî şartlar altında yaşayan diğer bölge ülkelerinde de, baskıcı yönetimlerin demokrasi talebinde bulunan vatandaşlar tarafından yerinden edilebileceğine dair umudun yeşermesine neden olmuştur (Koçak, 2012, 26).

Öte yandan, Tunus'ta yönetim karşıtı grupların oluşumun tarihsel bir altyapısı bulunduğunu, sosyal, ekonomik ve siyasi bir takım gelişmelerin bu yönetim karşıtı gruplaşmanın oluşmasında etkili olduğunu da ayrıca belirtmek gerekmektedir.

Bu bağlamda, kısaca bu gelişmeler ele alınabilir. Tunus'un bağımsızlık sonrası döneminde Burgiba'nın ardından Cumhurbaşkanlığına seçilen ikinci lider olan Zeynel Abidin'in 1990'lı yllardan itibaren düzenli bir şekilde muhalefeti sindirme politikasına yönelmesi, aslında kendisine karşı bir toplumsal gruplaşmanın ortaya çıkmasına yol açmıştır. Örgütlü bir şekilde hareket etmeyen ancak ekonomik nedenlerden ötürü muhalif konumda bulunan kesimlerin sayısı her geçen gün artmıştır. $\mathrm{Bu}$ kapsamda, Tunus'taki devrim hareketinin, yıllardır geri kalan ve siyasal barışın bir türlü sağlanamadığı, Güney ve Batı bölgelerinde başlaması da dikkat çekici bir olgudur (Ayhan, 2012, 75).

Ayrıca, Zeynel Abidin yönetiminin, eğitimli gençlerin işsizlik sorununa çözüm bulamaması, kayıt dışı sektörlerde düşük ücretli çalışanların çoğalması, gelir dağılımındaki adaletsizliğin artarak büyümesi ve bölgeler arası gelişmişlik farklarının derinleşmesi gibi önemli konularda çare bulamaması da yönetim karşıtı grupların oluşumunda ve ayaklanmaya giden süreçte etkili olmuştur (Koçak, 2012, $30)$.

Tunus'taki halk hareketi, Tunus'un orta bölgesinde bulunan ve 40.000 sakini olan, Sidi Bu Zeyd adlı küçük bir kasabada yaşayan 26 yaşındaki işportacı Muhammed Buazizìnin, 17 Aralık 2010'da meyve sebze tezgâhına bir kez daha el konulması ve maruz kaldığı kötü muamele üzerine kendisini ateşe vermesi ile başlamıştır (Kızmaz, 2014, 66).

Buazizi'nin eylemiyle birlikte birçok farklı gruptan bireyler ve muhalif siyasîler Bin Ali hükümetini protesto etmek üzere sokak ve meydanlarda toplanmaya ve gösteriler düzenlemeye başlamıştır (Koçak, 2012, 28).

Protestolar yönetimin baskıcı tavrına bir karşı tepki olarak başlamışken, kolluk birimleri tarafindan kaba kuvvetin daha fazla kullanılması, tepkiyi iyice alevlendirmiş ve sonuçta önü alınamayan bir kısır döngünün kapıları aralanmıştır (Koçak, 2012, 41).

Protesto gösterilerini durduramayan Zeynelabidin Bin Ali, çok sayıda insanın hayatını kaybetmesi üzerine, 14 Ocak 2011'de Tunus'u terk etmek zorunda kalmış ve ülkede katı laikliğin kurucularından biri olmasına rağmen ironik bir biçimde Suudi Arabistan'a iltica etmek zorunda kalmıştır (Ulutaş ve Torlak, 2011, 7).

Sonuç olarak Tunus'ta kimilerine göre Yasemin Devrimi kimilerine göre Arap Baharı kimilerine göre de Facebook devrimi olarak adlandırılan ve Buazizi’nin eyleminden Bin Ali'nin yurt dışına kaçmasına kadar geçen süreçte yaşanan gelişmelere bakıldığında, halkın ilk günlerde yönetimi devirmekten ya da değiştirmekten ziyade, yönetimin var olan baskıcı uygulamalarını ve ağır yaşam koşullarını protesto etmek amaçlı toplandığı anlaşılmaktadır. Kolluk birimlerinden olan emniyet teşkilatının sokaklarda toplanan kalabalı̆̆1 silah kullanarak zorla dağıtmaya başlamasından sonra ise protesto gösterileri münferit bir eylem olmaktan çıkarak, tsunami gibi giderek artan bir şekilde kitlesel bir siyasî eylem dalgasına dönüşmüsstür. Başka bir ifadeyle, Tunus’ta 2010 yllının sonunlarında başlayan gösteriler, Ocak 2011'in ortalarına gelindiğinde pek de öngörülemeyen ve planlanmayan bir 
Çapar, S., \& Koca, M. (2020). Yeni toplumsal hareketlerin farklı ülkeler üzerindeki etkileri: Tunus, Mısır, Türkiye ve Fransa'dan örnekler. Journal of Human Sciences, 17(2), 642-658. doi:10.14687/jhs.v17i2.5986

noktaya evrilerek, yönetimin değişimi talebinin ön plana çıkartıldığı iktidar karşıtı bir ayaklanma niteliğine bürünmüştür (Koçak, 2012, 42).

\subsection{Misir}

Misır, kültürel, fikirsel ve jeopolitik konumu bakımından Ortadoğu'nun en önemli ülkelerden birisi konumundadır (Sınmaz, 2019, 2). Arap Baharı olarak adlandırılan 5. demokratikleşme dalgasında ${ }^{4}$ bölgedeki konumu nedeniyle yine ön plana çıkan bir ülke olmuştur (Kızmaz, 2014, 69).

1 milyon kilometrekarelik yüzölçümü ile \% 84’ü Sünni Müslüman olan ülkede çoğunluğu ortodoks olan \% 15 civarında Hristiyan nüfus da yaşamaktadır. Olayların başlamasından önce yapılan son nüfus sayımında 84 milyon 400 bin olarak tespit edilmiştir. Ülke nüfusu, genel olarak yoksul kategoride sınıflandırılmaktadır. Arap Baharının başladığı günlerde Mısır'da kişi başına düşen GSYH 6 bin dolar civarındadır (Taştan, 2018, 125).

Tunus'ta Muhammed Buazizi'nin kendisini ateşe vermesi sonucunda gelişen iktidar karşıtı gösteriler Mısır'a sıçramıştır. Yaklaşık 30 yıldır iktidarda bulunan Hüsnü Mübarek gösterilerin başladığ1 tarih olan 25 Ocak 2011'den 18 gün sonra, 11 Şubat 2011 tarihinde istifa etmek zorunda kalmıştır (Kurun, 2019, 2).

Misır'da yaşanan protestolar sırasında taleplerin genel olarak iktidarın yozlaşması, ekonomik durgunluk, yolsuzluk, ahbap-çavuş ilişkileri, işsizlik, ekonomik ve cinsiyet eşitsizliği ile antidemokratik ve baskıcı yönetim konuları karşısında geliştiği görülmüş ve bu minvalde ülkedeki protestolarda 'ekmek' sloganının yanında en fazla kullanılan iki sloganın, 'hürriyet' ve 'insan onuru' olduğu görülmüsstür (Özen, 2015: 18-19). Aynı zamanda, Mübarek'in istifasına giden süreçte sosyal medya başat bir role bürünmüştür (Kızmaz, 2014, 69).

Mısır'da 2011 yilında yaşanan toplumsal hareketlerin tarihsel arka planındaki ekonomik gerekçeleri; Cemal Abdülnasır'ın 1950’lerde ortaya çıkardığ1 “Arap Sosyalizmi”, sonrasında ise Enver Sedat'ın 1970'lerde hayata geçirdiği "El İnfitah" adını verdiği ekonomik programların bazı kısmi başarılarına rağmen uzun dönemde Misır'da yaşayan halkın içinde bulunduğu fakirlik sorununa çözüm üretememesi sonucunda, sosyal adaletin giderek bozulması ile yolsuzluk ve rüşvetin artması olarak sıralamak mümkündür (Sinmaz, 2019, 3).

Ayrıca Mısır'da halk hareketinin başlamasını siyasi olarak motive eden pek çok olay da yaşanmıştır (Telli, 2012, 77). Yönetici kesimin ideolojik yapısına muhalif görülen tüm İslamcı, liberal ve solcu grupların farklı zamanlarda işkence, zorla kaybedilme ve keyfî tutuklamalara maruz kalması, bu siyasi sebeplerin başında gelmiştir (Sınmaz, 2019, 4).

Tunus'ta yaşanan olayların Mısır'a sıçraması ve tarihsel bir süreç içerisinde yaşanan ekonomik sıkıntılar ve siyasi taleplerin giderek artan bir hoşnutsuzluk meydana getirmesi söz konusu olmuştur. Bununla birlikte Misır'da Ulusal Polis Günü olan 25 Ocak'ta protestolar düzenlenmiş ve düzenlenen bu protestolara halk tarafindan "işkenceye, yoksulluğa, yolsuzluğa ve işsizliğe isyan günü” adı verilmiştir ${ }^{5}$ (Telli, 2012, 78).

Tahrir Meydanı'ndaki kalabalığın protestoların ikinci gününde daha da artmasıyla birlikte polis ile göstericiler arasındaki çatışmalar da giderek şiddetlenmiştir. Protestoların şiddetlenmesi ve çatışmaların artması ile birlikte Mübarek yönetimi, facebook ve twitter gibi protestocuların bir araya gelerek örgütlenmesinde en önemli rollerden birini üstlenen sosyal medya platformalarına erişimi engellemiştir (Telci, 2012, 218-219).

27 Ocak'ta ülkede mobil iletişim bağlantılarının kesilmesine rağmen 28 Ocak'ta gerçekleştirilen ve “Öfke Günü” olarak adlandırılan büyük çaplı eylemlere binlerce kişi katılmıştır. Kolluk birimlerinden olan polisin biber gazı, gerçek mermi, tazyikli su gibi farklı yollar ile göstericilere müdahale etmesi nedeniyle taraflar arasında uzun süreli çatışmalar yaşanmış, ancak bu sırada ordu,

\footnotetext{
${ }^{4}$ Telli (2012) Mısır Devriminde Sosyal Medyanın rolü adlı makalesinde Samuel Huntington’un “3. Dalga” teorisinden yola çıkılarak Renkli Devrimlerin 4. Demokratlaşma Dalgası olarak kabul edildiğini, "Arap Baharı” kapsamındaki halk ayaklanmalarının da "5. Demokratlaşma Dalgası" olarak nitelendirildiğini ifade etmiştir.

5 Telli (2012) 25 Ocak’ta gerçekleştirileceği duyurulan protesto çağrısına günler öncesinden Twitter üzerinden 78 bin kişinin olumlu yanıt verdiğini, Twitter ve YouTube üzerinden yapılan paylaşımların dünya kamuoyunun da gelişmeleri yakından takip etmesine imkan sağladığını ifade etmiştir.
} 
Çapar, S., \& Koca, M. (2020). Yeni toplumsal hareketlerin farklı ülkeler üzerindeki etkileri: Tunus, Mısır, Türkiye ve Fransa'dan örnekler. Journal of Human Sciences, 17(2), 642-658. doi:10.14687/ihs.v17i2.5986

çatışmalara yakın olmasına rağmen polis ve sivil halk arasındaki olaylara hiçbir şekilde müdahalede bulunmamıştır (Sınmaz, 2019, 5-6).

Tarihler 2 Şubat'’ gösterdiğinde ise Tahrir Meydanında "Deve Savaşı" olarak adlandırılan olay gerçekleşmiştir. Deve Savaşı olarak adlandırılan bu olaylarda Hüsnü Mübarek taraftarları deve ve atlarla meydana gelerek özellikle Müslüman Kardeşler ve Al-Ahli takımının Ultralar olarak bilinen taraftar grubunun yer aldığı 20.000 kişilik gösterici kalabalığına bıçak, kilıç ve demir sopa gibi farklı aletlerle saldırmışlardır (Telci, 2012, 220).

10 Şubat 2011 tarihine gelindiğinde ise Misır'da Yüksek Askeri Konsey bir bildiri yayınlayarak göstericilerin isteklerininin tanındığını belirtmiş ve bu açıklama ile birlikte göstericilerin genelinde, Hüsnü Mübarek'in gidişinin yakın olduğu yorumları artmaya başlamıştır (Telci, 2012, 221).

Netice itibarıly Sınmaz (2019, 3), “Arap Baharı olarak adlandırılan süreçte gerçekleştirilen ve Mübarek'in iktidarı bırakması ile sonuçlanan gösterilerin, halkın taleplerinin yıllarca görmezden gelindiği, üstelik halkın sürekli kontrol altında tutulmaya çalışıldığı ve bunun için de her türlü yolun meşru sayıldığ bir sürecin sonunda gerçekleşen doğal bir öfke patlamasından başka bir şey olmadığını" ifade etmiştir.

\subsection{Fransa}

Sarı Yelekliler hareketi olarak adlandırılan protestolarının başladığı 2018 y1lında 66,9 milyonluk bir nüfusa sahip olan Fransa'nın (eurostat, 2020), 2017 yll verilerine göre GSYH'sı kişi başina 44.200 dolar olarak hesaplanmıştır (MFA, 2020).

Fransa'da gerçekleşen ve Sarı Yelekliler hareketi olarak adlandırılan görünüşte barışçıl ve göz alıcı olan protestolar, Paris'e getirdiği sivil yıkımın yanı sıra eşi benzeri görülmemiş şiddet hareketleri ile birlikte dünyada da şok etkisi yaratmış ve bu hareketin ardılları da yaşanmıştır ${ }^{6}$ (Sikharulidze, 2019, 1).

17 Kasım 2018 tarihinde 280 binden fazla kişinin Fransa'da sokağa çıkıp hükümeti protesto etmesiyle başlayan Sarı Yelekliler hareketi ${ }^{7}, 2008$ yılında başlayan ekonomik kriz ve Arap Baharının açtığı yolda, Avrupa'daki kemer sıkma politikaları karşısında belki de en keskin toplumsal hareketi oluşturmuştur. Hatta bu protestolar ile ilgili olarak Sarı Yelekliler hareketinin Fransa'nın 1968 yılından itibaren yaşadığ1 en büyük toplumsal olay olduğuna ilişkin genel bir iddia da bulunmaktadır (Gürcan, 2019, 439).

Aslında gösterilerin görünür yüzünde akaryakıt fiyatlarındaki artış olsa da kemer sıkma paketleri, vergilerin artırılması, sosyal yardımların kısılması, geçim sıkıntısı, işadamlarına yönelik vergi muafiyeti uygulamaları, çalışma koşullarının esnekleștirilmesi, sosyal dengesizlikler protestoların arkasındaki asıl nedenleri oluşturmuş (Çimen ve Bakan, 2019, 95-96) güvenlik güçlerinin ilk eylemleri şiddet kullanarak bastırması ise protestocular arasındaki öfkeyi pekiştirmiş ve Sarı Yelekliler hareketinin daha da ivme kazanmasına siyasal bir olanak sağlamıştır (Gürcan, 2019, 444).

Göstericilerin temel taleplerini ise esnafları destekleyici önlemlerin alınması, emeklilik maaşlarının 1.200 Euro'nun altında olmaması, büyük şirketlerin vergilerini ödemesi, işsiz olanlar için iş imkânlarının sağlanması, gaz ve elektrik fiyatlarının düşürülmesi, emeklilik yaşının 65 yaş olması, referandumun anayasaya girmesi, bazı anayasa maddelerinin değiştirilmesi, şehir merkezlerinde ev kiralarının düşürülmesi ve uluslararası anlaşmaların da halk oylamasına götürülmesi oluşturmuştur (Çimen ve Bakan, 2019, 98-99).

Faytre Kasım 2018'den itibaren Fransa sokaklarında görülmeye başlanan Sarı Yelekliler'in protestolarının her ne kadar büyük bir katılımla gerçekleşmese de gösterilerin yöntemleri ve evrimininin farklı bir durumu ortaya koyduğunu, birçoğu hayatında ilk defa protestoya katılan eylemcilerin hafta sonlarında gösteriler düzenlediklerini; ana caddeleri, döner kavşakları ve otoyol

\footnotetext{
${ }^{6}$ Sikharulidze (2019) Sarı Yelekliler hareketinin daha sonra Avustralya, Kanada, Belçika Mısır, Almanya, Sırbistan, Tunus ve Finlandiya’ya da sıçradığını söylemiştir.

${ }^{7}$ Göstericilere Sarı Yelekliler denmesinin nedeni her sürücünün kaza veya yoldaki diğer sorunlar durumunda araçlarında acil durum yeleği olarak sarı yelek bulundurması zorunluluğundan doğmuştur.
} 
Çapar, S., \& Koca, M. (2020). Yeni toplumsal hareketlerin farklı ülkeler üzerindeki etkileri: Tunus, Mısır, Türkiye ve Fransa'dan örnekler. Journal of Human Sciences, 17(2), 642-658. doi:10.14687/jhs.v17i2.5986

girişleri gibi önemli yerleri kapatarak gerçek bir polis gibi diğer vatandaşlara çeşitli yasaklamalar uygulamaya ve çeşitli emirler vermeye başladıklarını söylemiştir (Faytre, 2018).

Tüm şiddet görüntülerine ve olaylar süresince 11 kişinin ölmesine rağmen sonuçta "Sar1 Yelekliler"in protestoları kısa sürede sonuç almış ve Macron geri adım atmak zorunda kalmıştır. Protestolarda planlanan petrol vergisi zammının, 6 ay ertelenmesi teklifi tepkiyle karşılandığından, bu zam tamamen iptal edilmek zorunda kalınmış, Fransa Başbakanlık Ofisi, Başbakan Edouard Philippe e in ülke genelinde akaryakıta getirilen vergi zamlarının geri çekileceğini duyurmuştur.

Bunun yanı sıra Macron, şirketlere herhangi bir ek maliyet yükü yüklemeden asgari ücrete 2019 itibarıyla, aylık 100 Euro zam yapılacağını açıklamış ve ülke çapında ki işverenlerden çalışanlarına dönük yıl sonunda prim ödemesini isteyerek 2 bin Euro'nun altındaki emeklilik maaşlarından artık kesinti yapılmayacağını ilan etmiştir (Çimen ve Bakan, 2019, 97-98).

Ancak hükümetin uzlaşı ve tüm protestoları iptal çağrılarına rağmen, protestoların ilerleyen zamanlarda da devam etmesiyle birlikte başlangıçtaki ekonomik talepler de daha geniş ve çeşitli taleplere dönüşmeye başlamış, modern tarih boyunca diğer protesto hareketlerinde olduğu gibi yakıt fiyatlandırması gibi somut sosyal şikâyetlerden Macron'un istifasını isteyen siyasi taleplere doğru bir süreç gelişmiştir (Sikharulidze, 2019, 1-2).

Sonuç olarak Sarı Yeleklilerin eylemleri, Fransız yönetimince başlangıçta hafife alınmış, olayların büyümesiyle ciddiye alınarak bazı önlemler alınmış olsa da protestolarının nereye kadar devam edeceği ve ne yönde dönüşeceğini zaman ve gelişmeler tayin edecektir (Çimen ve Bakan, 2019, 99).

\subsection{Türkiye}

21. yüzyılın başlangıcından itibaren dünyanın farklı bölgelerinde benzerlerine rastlanmaya devam edilen toplumsal hareketler dalgasına Türkiye, 2013 yllında yaşanan Gezi Parkı Protestoları ile maruz kalmıştır. Aktörleri, hareket biçimi, siyasal alanı etkileme çabası ve talepleri ile birlikte değerlendirildiğinde Gezi Parkı eylemlerinin de güncel sivil toplumun alanı içerisine girdiği ve yeni toplumsal hareket biçimlerinden biri olduğu sıklıkla dile getirilmiştir (Öngör, 2018, 83).

Gezi parkı protestolarının başladığı 2013 yılında yaklaşık 76,7 milyonluk bir nüfusa sahip olan Türkiye'nin (TÜIK, 2018), kişi başına düşen GSYH's1 ise o dönemde 12.510 dolar olarak gerçekleşmiştir (Worldbank, 2020).

Aslında Gezi Parkı eylemlerini başlatan süreç 2011 yılında İstanbul Büyükşehir Belediye Meclisi'nin Taksim Meydanı Yayalaştırma Projesi kapsamında hazırlanan tadilat planı teklifinin oy birliğiyle kabul edilmesi üzerine başlamakla birlikte ${ }^{8}$ (Öngör, 2018, 83), arka planında Emek Sinemasının yıkılması, tarihi İnci Pastanesi'nin kapanması ve Sulukule Kentsel Dönüşüm Projesi gibi gelişmeler de bulunmaktadır (Ete ve Taştan, 2013, 23).

Bayhan (2014: 33), Gezi Park1 protestolarının her ne kadar temelinde çevre duyarlılığı, kalkınma ve tüketim gibi neoliberal politikalara karşıllk verecek şekilde başlamış olsa da, daha sonralarında sadece iktidara muhalif olanların bir araya geldiği ve şiddeti merkezine alan bir eylem biçimine dönüşerek isyana doğru evrildiğini söylemiştir.

Aslan, Taylan ve Baştuğ $(2016,153)$ ise Gezi Parkı protestolarının temelinde çevreci bir güdü bulunmadığını, eylemlerin daha çok siyasi, ekonomik ve ideolojik bir karşıtlık taşıdığını, dolayısıyla bu siyasi, ekonomik ve ideolojik düşünce anlayışının asıl hedefinin iktidar karşıtı bir anlayış meydana getirmek ve bu şekilde iktidarı değiştirmek olduğuna işaret etmiştir.

27 Mayıs 2013 tarihinde yaklaşı 50 kişilik bir gösterici grubunun, Taksim Meydanı Yayalaştırma Projesi'ni protesto etmek üzere harekete geçmesiyle başlayan protestolar (Ete ve Taştan, 2013, 22) aralıklarla 30 Ağustos 2013 tarihine kadar sürmüş ve protestoların zirvesini oluşturan üç haftalık süreç içerisinde biri polis olmak üzere sekiz kişi yaşamını yitirirken yaklaşık olarak 10 bin kişi de yaralanmıstır (BBC, 2019).

\footnotetext{
8 Öngör (2018) Ayata ve diğerlerine yaptığı atıfta bu projenin en önemli değişikliğinin Gezi Parkı’nın kaldırılarak yerine Topçu Kışlası'nın yapılacak olması olduğunu söylemiştir.
} 
Çapar, S., \& Koca, M. (2020). Yeni toplumsal hareketlerin farklı ülkeler üzerindeki etkileri: Tunus, Mısır, Türkiye ve Fransa'dan örnekler. Journal of Human Sciences, 17(2), 642-658. doi:10.14687/jhs.v17i2.5986

Protestocuların profili açısından çözümlemeler yapılmıştır. Bayhan $(2014,33)$ protestocuları üç ayrı kategoride sınıflandırmış ve protestocuların çekirdeğini; sahip oldukları ekonomik ve kültürel ya da beşeri sermayeleri bakımından toplumun orta sınıfı olarak adlandırılabilecek olan kentli, öğrenci ve beyaz yakalı genç kuşak ücretliler ile sanatçılar, mimarlar ve bu grupların üye oldukları dernekler, meslek odaları gibi platformların, bahsedilen çekirdek grubun dışında kendilerini siyasi yelpazenin solunda tanımlayan siyasi partiler, gençlik platformları ve örgütler ile bunların seçmeni veya sempatizanlarını, son halkada ise gösterilere doğrudan katılım göstermemekle birlikte farklı toplumsal aidiyetlere sahip, bu nedenden ötürü de farklı politik, ekonomik ve sinıfsal beklentiler sahip olan Hükümete kızgın kişilerin olduğunu ifade etmektedir.

Gezi Parkı Eylemleri sırasında protestocuların talepleri açısından 3 Haziran 2013 tarihinde Taksim Dayanışması grubu tarafından yayınlanan basın açıklaması esas alınabilir. Bu taleplerin, Gezi Parkı'nın mevcut halinin korunması ve Atatürk Kültür Merkezi'nin yıkılmaması, eylemler sırasında yaşananlardan dolayı başta İstanbul Valisi ve Emniyet Genel Müdürü olmak üzere sorumluların istifa etmesi, gözaltına alınanların serbest bırakılması, toplantı ve eylem yasağının sona erdirilmesi ve ifade özgürlüğünün önündeki tüm engellerin kaldırılması gibi taleplerin sıralandığ1 görülmüsstür (BBC, 2019).

Ete ve Taştan (2013)'a göre ile eylemlerin gelişim seyri şöyle olmuştur: Protestoların başladığ1 ilk günlerde amaçlarını "Gezi Parkı’nın korunması olarak deklare eden grup, barışçıl yöntemlerle eylemlerini polisle çatışmaların yaşandığı 27-31 Mayıs tarihlerine kadar sürdürmüştür.

Siyasallaşma aşaması olarak da değerlendirilebilecek olan ve Gezi Parkı eylemlerinin doruğuna ulaştığı 1 Haziran - 15 Haziran 2013 tarihlerini kapsayan iki haftalık zaman aralığınının ayırt edici özelliği ise gösterilerin hedefleri, coğrafi özellikleri ve eylemci topluluğunun demografik niteliği itibariyle hızlı ve geniş çaplı bir değişim yaşaması ve devamında da Hükümet karşıtı protesto eylemlerine dönüşmesi olmuştur.

Zayıflama aşaması olarak adlandırılabilecek olan dönem ise 15 Haziran akşamı Gezi Parkı'na yönelik uygulamaya konulan polis müdahalesinden sonra eylemlerin tesiri, amaçları ve boyutlarında meydana gelen hızlı inişi ve daralmayı ifade etmiştir Sokak muhalefeti ile amaçlarına ulaşamayan protestocular, anılan tarihten itibaren kısmi bir şekilde farklı arayışlar içine girmiş ve bu kapsamda şiddeti merkezine alan eylem biçimlerinden uzaklaşarak mahalle toplantıları ve bağımsız seçim kampanyaları gibi farklı arayışlar içinde olmuşlardır" (Ete ve Taştan, 2013, 21-22).

Genel olarak özetlenirse, Öngör $(2018,93)$ 'ün de ifade ettiği üzere kentsel dönüşüm karşıt1 bir çevre hareketi olarak başlayan protestolar, muhalefet eksikliğinin de etkisiyle kitleselleşmiş ve siyasal alanı etkileme çabaları, eylemlerin muhalif dili ile Gezi Parkı Protestoları, 21. yüzyılda sivil toplum alanının içerisine giren yeni bir toplumsal hareket olarak tarihteki yerini almıştır.

\section{GENEL DEĞERLENDİRME}

Çalışmanın bu bölümünde bir önceki bölümde incelenen ülkelerin yerleşik demokrasi kültürü çerçevesinde siyasal hayatlarına çok kısa bir bakış gerçekleştirilecektir.

Bu kapsamda Tunus'tan başlayacak olursak Ulutaş ve Torlak, 1957 yllında Tunus Cumhuriyeti'nin kurulmasıyla Habip Burgiba'nın ilk Cumhurbaşkanı olarak seçildiğini, 1975 yllında ise Burgiba'nın, meclis tarafindan "Ömür boyu Cumhuriyetin Cumhurbaşkanı”" olarak seçilerek tek parti rejiminin kurulduğunu aktarmışlardır. 1987 yllında Başbakan olan Zeynelabidin Bin Ali’nin, sağlık sorunlarından ötürü görevi bırakan Cumhurbaşkanı Burgiba'dan görevi alması ile birlikte modern Tunus'un yakın tarihinde gerçekleşen bu sürecin "sessiz devrim" olarak kayıtlara geçtiğini ve 1989 yılında Bin Ali’nin Cumhurbaşkanlığı seçimlerini kazanarak partisi olan Anayasal Demokratik Parti'nin meclisteki tüm sandalyeleri kazandığını ve Cumhurbaşkanı Bin Ali'nin, 1994, 1999 ve 2004'te Cumhurbaşkanlığ1 görevine tekrar seçildiğini aktarmışladır (Ulutaş ve Torlak, 2011, 6).

Mısır'da ise demokrasi kültürü ile demokratik kurum ve kuruluşların gelişimi özellikle 18. yüzyıldan itibaren etkisini artıran Batı kaynaklı modernitenin dikotomileri ile otoriter bir nitelik taşıyan siyasi elitlerin talep ve yaşam tarzları arasında sıkışıp kalmıştır. Bu arada kalmışlık ülkede demokrasiyi çoğu zaman ulaşılması gereken bir amaç olmaktan çıkarmış ve demokratik gelişim ve dönüşümü 
Çapar, S., \& Koca, M. (2020). Yeni toplumsal hareketlerin farklı ülkeler üzerindeki etkileri: Tunus, Mısır, Türkiye ve Fransa'dan örnekler. Journal of Human Sciences, 17(2), 642-658. doi:10.14687/jhs.v17i2.5986

gerçekleştirmesi beklenen organları da iktidarın, muhalefetin ve hatta yabancı güçlerin oyun alanı içinde bulunduğu bir iktidar kavgasının aracı haline getirmiştir.

Modern Misır'n demokratik hayatı “özellikle 1952 yllında Nasır önderliğinde gerçekleşen darbeden sonra altyapısı ve fikri temelleri daha da ön plana çıkan, Enver Sedat ve Mübarek döneminde ise yukarıdan planlanan ve kontrollü bir şekilde gerçekleştirilen açılım politikaları ve reformlarla ayakta tutulmaya çalışlan ve temelinde hantal, doğu despotizmini yine doğu tarzı üretim biçimleriyle harmanlamış, otoriteye dayanan ve elitist bürokratik olarak kabul edilen bir devlet organizasyonunun yanında geleneksel adam kayırmacilı̆̆ önceleyen bir siyasi kültürden ayrışmayan” bir çizgide sürdürmüştür (Koldaş ve Köprülü, 2011, 38-40).

Kita Avrupası'nın ilk modern demokrasisini yaşamış olan Fransa ise 1789 Devrimi ile birlikte büyük bir oranda karmaşık bir siyasal tarihe girmiş ve aradan geçen 230 yllık zaman zarfı boyunca farklı anayasal değişimler yaşamıştır. Bu süreç içerisinde on beş farklı anayasa ile yönetilen Fransa (Şencan, 2017, 25-28) mutlak monarşi ve devrimci diktatörlükten parlamenter sisteme ve yar1 başkanlık sistemine doğru evrilen bir siyasal yaşam geçirmiştir (Ekinci, 2016, 149).

Feodal devletin ortadan kaldırılması ile birlikte herkesten eşit vergi alınması, herkesin yasa önünde eşit olması, keyfi tutuklamalar ve cezalandırmaların yasaklanması, vatandaşların her memuriyete yükselebilmesi imkânının sağlanmasında eşitlik ilkesinin geçerli olması gibi İnsan ve Yurttaş Hakları Bildirisi'nin dayanmış olduğu bu ve buna benzer ilkeler (Dayan, 2017, 10) ile 1791 Anayasasının getirmiş olduğu kuvvetler ayrillğı ilkesi ile Fransa Kıta Avrupası'nda demokrasinin öncülüğünü yapmıştır (Ekinci, 2016, 158).

Türkiye'de yerleşik demokrasi kültürünün başlamasının vatandaşlara verilen haklar bağlamında tarihsel gelişimine bakacak olursak 1808 tarihli Sened-i İttifak ile ilk kez vergilerin herkesten adil toplanacağı taahhüdünde bulunulmuştur. Vatandaşlara verilen haklar noktasında bu süreç 1839 tarihli Tanzimat ve 1856 tarihli Islahat Fermanı ile devam etmiş ve demokratik kültürün yerleşmesi noktasında 1876 tarihli Kanun-i Esasi Türk demokrasi hayatının önemli noktalarından birisi olmuştur.

Türk demokrasi hayatının gelişiminde II. Meşrutiyet'in ilanı ile kuvvetler ayrılığının bir göstergesi olan Meclis-i Mebusan ön plana çıkmış (Çapar, 2015, 147), Cumhuriyetin ilanı ve 1946 yılında çok partili siyasal yaşama geçilmesi ile demokrasi kültürü toplumsal hayata iyice yerleşmiştir.

Sonuç olarak yeni medya olarak da adlandırılan sosyal medyanın ortaya çıkışı sonrasında meydana gelen toplumsal hareketler çerçevesinde yeni bir birey tipinin evrimleşerek ortaya çıması (Babacan, 2015: 303) toplumsal hareketlerin içerik ve yönünü değiştirerek demokrasi kültürü zayıf olan ülkelerde iktidar değişimlerine neden olabilmiştir. Bu kapsamda Tunus ve Misır gibi ülkelerde muhalefet eksikliği, temel hakların sunumundaki eksiklikler gibi bazı unsurlar dolayısıyla demokrasi kültürünün hala yerleşememesi, toplumsal hareketler yoluyla iktidar değişikliklerine neden olabilirken, Türkiye ve Fransa gibi ülkelerde demokrasi kültürünün toplumsal alana yerleşmesi, benimsenmesi ve uygulanması sonucunda toplumsal hareketlerin -normal seçim dönemleri haricinde- iktidar değişimlerine neden olmadığını ifade edebilmek olasıdır.

\section{SONUÇ}

Toplumsal yapılar arasında devam edegelen çatışmalardan oluşan ve ortaklaşa eylem biçimlerinde kendisini gösteren hareketler olarak tanımlanabilen toplumsal hareketlerin, tarihsel ve sosyolojik gelişim süreçlerine bakı1dığında politik ve ekonomik ağıllıklı konulardan kimlik, temel hak ve özgürlükler, demokratikleşme, çevre gibi daha tematik ilgi alanlarına kaydığı görülmektedir.

Önceleri daha çok bir sınıfın öncülüğünde eylemsellik gösteren toplumsal hareketler, 1960’1ı yıllardan itibaren özellikle de 2000 'li yıllar sonrasında taleplerin içeriğindeki değişim ile birlikte daha geniş bir toplumsal tabana yayılmış ve orta sınıfin yükselen öncüllüğüne şahit olunmuştur.

Son zamanlarda yeni olarak da kavramsallaştırilan toplumsal hareketler belli bir sınıfin liderliğinden ziyade iletişim teknolojilerindeki gelişmelerden faydalanarak daha geniş bir tabana yayılmış, etkileri ve sonuçları itibarıyla da kamusal ve sivil toplum alanlarındaki görünürlüğü buna paralel olarak artmıştır. 
Çapar, S., \& Koca, M. (2020). Yeni toplumsal hareketlerin farklı ülkeler üzerindeki etkileri: Tunus, Mısır, Türkiye ve Fransa'dan örnekler. Journal of Human Sciences, 17(2), 642-658. doi:10.14687/jhs.v17i2.5986

Günümüzün küreselleşen dünyasında iletişim teknolojilerindeki baş döndürücü gelişmeler de dünyanın herhangi bir yerindeki sorunu farklı coğrafyalara taşımakta katalizör görevi görmüş, toplumsal hareketlerin yayılım ve etkilerini de artırmıstır.

Yeni toplumsal hareketlerin eskiye nazaran eylem biçimlerindeki değişim, örgütlenme tarzındaki farklıllklar ve iktidarı ele geçirmekten ziyade daha spesifik talepleri doğrultusunda siyasal alanı etkileme çabaları ise demokrasi kültürünün yerleşik olup olmamasına göre farklı ülkelerde farklı sonuçlara yol açmışır.

Bu kapsamda Arap Baharı ile başlayan süreçte, toplumsal hareketler çıkış noktaları itibariyle Mısır ve Tunus gibi demokrasi kültürü yerleşmemiş ülkelerde talepler bağlamında hızla siyasallaşarak yönetimlerin devrilmesine veya darbeler ile değissmesine neden olurken, Gezi Parkı olayları ve Sarı Yelekliler hareketlerinde de görüldüğü üzere Türkiye ve Fransa gibi uzun bir demokrasi geçmişine ve kültürüne sahip olan ve bu kültürü içselleştirmiş ülkelerde -süreç içerisinde taleplerin siyallaşarak iktidar değişikliği taleplerine evrilmesine rağmen- yönetim değişikliğine neden olmamıştır.

Bu bağlamda, kökleşmiş bir demokrasi geçmişine ve içselleştirilmiş bir demokrasi kültürüne sahip olan ülkelerin bundan yoksun ülkelere kiyasla toplumsal hareketlerin iktidar değişikliğine evrilen talepleri karşısında demokratik ilke ve esaslara daha sadık oldukları ifade edilebilmektedir.

\section{KAYNAKÇA}

Aktaş, M. (2015). Demokrasi Kavramına Eleştirel Bir Bakış. Muş Alparslan Üniversitesi Sosyal Bilimler Dergisi, 3 (1), 87-105.

Aminzade, R. ve D. McAdam (2002). Emotions and Cotentious Politics. Mobilization, 7 (2), 107-109. Aslan, C. (2016). Sosyal Hareketler Sosyolojisi - Toplumsal Fay Hatlarmm Anatomisi, Adana: Karahan Kitabevi.

Aslan, S., Ö. Taylan ve D. Baştuğ (2016) Gezi Parkı Eylemlerinin Farklı Boyutlarıyla Bir Değerlendirmesi. Birey ve Toplum, Güz 2016, 6 (12), 153-177.

Ayhan, V. (2012). Tunus İsyanı: Arapların Devrim Ateşini Yakması. Ortadoğu Etütleri, Cilt 3, No 2, Ocak 2012.

Babacan, M. E. (2015). Yeni Medya Bağlamında Toplumsal Hareketler ve Yeni İnsanın Karakter Analizi. Folklor/Edebiyat Dergisi, 21 (83), 295-307.

Bayhan, V. (2014). Yeni Toplumsal Hareketler ve Gezi Park1 Direnişi, Birey ve Toplum, Bahar 2014, 4 (7), 23-58.

BBC (2019). https://www.bbc.com/turkce/haberler-turkiye-44304326, (08.10.2019).

Collas, A. (2002). International Civil Society Movements in World Politics, Cambridge: Polity Press.

Crick, B. (2002). Demokrasi, Kültür Kitaplığ1: 113, Ankara: Dost Kitabevi.

Çapar, S. (2015) Türkiye ve Fransa'da Neo-liberal Dönemde Mülki İdare, Ankara: TİAV Yayınları.

Çayc1, B. (2015). Yeni Dijital Çağda Toplumsal Hareketlerde Meydana Gelen Dönüşüm. The Turkish

Online Journal of Design, Art and Communication, January 2015, 5 (1), https://acikerisim.iku.edu.tr/bitstream/handle/11413/1128/Yeni $\% 20$ Dijital $\% 20 \%$ C3\% $\% 87$ a $\% \mathrm{C} 4 \% 9 \mathrm{Fda} \% 20$ Toplumsal $\% 20$ Hareketlerde $\% 20$ Meydana $\% 20$ Gelen $\% 20 \mathrm{D} \% \mathrm{C} 3 \% \mathrm{~B} 6 \mathrm{n} \%$ $\mathrm{C} 3 \% \mathrm{BC} \% \mathrm{C} 5 \% 9 \mathrm{~F} \% \mathrm{C} 3 \% \mathrm{BCm} \% 20 \% \mathrm{EF} \% \mathrm{BB} \% \mathrm{BF}$.pdf? sequence $=3 \&$ isAllowed $=\mathrm{y}$, (09.10.2019).

Çetinkaya, Y. D. (2018) Tarih ve Kuram Arasında Toplumsal Hareketler, içinde Toplumsal Hareketler - Tarih, Teori ve Deneyim, Ed.: Y. D. Çetinkaya, 4. Basım, İstanbul: İletişim, 15-61.

Çimen, H. ve S. Bakan (2019). Toplumsal Olayların Merkezi Fransa'daki Sarı Yelekliler Hareketi ve Protestoların Türkiye'ye Yansımaları. Gaziantep Üniversitesi İktisadi ve İdari Bilimler Fakültesi Dergisi, 1 (1), 80-107.

Dayan, H. (2017). Fransa, Trakya Üniversitesi Sosyal Bilimler Enstitüsü Kamu Yönetimi Anabilim Dalı, https://www.academia.edu/32073198/FRANSA.pdf (07.11.2019). 
Çapar, S., \& Koca, M. (2020). Yeni toplumsal hareketlerin farklı ülkeler üzerindeki etkileri: Tunus, Misır, Türkiye ve Fransa'dan örnekler. Journal of Human Sciences, 17(2), 642-658. doi:10.14687/jhs.v17i2.5986

Demiroğlu, E.T. (2014). Yeni Toplumsal Hareketler: Bir Literatür Taramas1. Marmara Üniversitesi Siyasal Bilimler Dergisi, 2 (1), 133-144.

Dirlik, A. (2018). Pasifik Perspektifinde Toplumsal Hareketler: Çağdaş Radikal Siyasetin Soyağacı Üzerine Düşünceler, içinde Toplumsal Hareketler - Tarih, Teori ve Deneyim, Ed.: Y. D. Çetinkaya, 4. Basım, İstanbul: İletișim 75-93.

Dolgun, U ve T. Sütlüoğlu (2014). Sosyal Medya ve Yeni Toplumsal Hareketler, Atatürk Üniversitesi Açık Öğretim Fakültesi, https://www.researchgate.net/publication/322386107 Sosyal Medya ve Yeni Toplumsal Hareketler, (17.10.2019).

Ekinci, E. (2016). Devrimden Günümüze Fransız Siyasal Sisteminin Evrimi. Kırkkkale Üniversitesi Sosyal Bilimler Dergisi, 6 (1), 149-171.

Ete, H. ve Ç. Taştan (2013). Kurgu ile Gerçeklik Arasinda Gez̧i Eylemleri, SETA Yayınları XXVII. Eurostat

https://ec.europa.eu/eurostat/databrowser/view/tps00001/default/table?lang=en, (24.01.2020).

Faytre, L. (2018). Sar1 Yelekliler Ne İstiyor? https://www.sabah.com.tr/yazarlar/perspektif/lonardfaytre/2018/12/01/sari-yelekliler-ne-istiyor, (26.09.2019).

Giddens, A. (2000). Sosyolojï, Çev.: C. Güzel, Ankara: Ayraç Yayınları.

Güçyetmez, M. (2017). Karşılaştırmalı Demokrasi Modelleri ve Hükümet Sistemleriyle İlişkisi. Hacettepe Hukuk Fakültesi Dergisi, 7 (1), 479-496.

Gürcan, E.C. (2019). Bir "Siyasal Süreç” Olarak Fransız Sarı Yelekliler Hareketinin Ortaya Çıkışı, Mülkiye Dergisi, 43 (2), 435-458.

Işık, G. (2016). Sanaldan Sokağa Toplumsal Hareketter, 2. Basım, Ankara: Nobel.

İnan, Afet (2010). Mustafa Kemal Atatürk Medeni Bilgiler Türk Milletinin El Kitabı, 2. Bask1, İstanbul: Toplumsal Dönüşüm Yayınları.

Kilıç, S. (2009). Kamuoyu Oluşum Sürecinde Sosyal Hareketler ve Medya. Niğde Üniversitesi İIBF Dergisi, 2 (2), 150-167.

Kızmaz, N. (2014). A ̆ğ Toplumu Bağlamında Orta Doğu'da Meydana Gelen Sosyal Hareketler. Toplum Bilimleri Dergisi, Temmuz 2014, 8 (16), 51-74.

Koçak, K. A. (2012). Yasemin Devrimi’nden “Arap Baharı”na Tunus. Yasama Dergisi, 7 (22), 22-61.

Koldaş U. ve N. Köprülü (2011). Arap İntifadası Mı?: Arap Dünyasindaki Toplumsal Hareketlerin İçsel, Bölgesel ve Uluslararası Dinamikleri. Akademik Ortadoğu, 6 (1), 23-61.

Komito, L. ve J. Bates (2009). Virtually Local: Social Media and Community Among Polish Nationals in Dublin. Aslib Proceedings: New Information Perpectives, 61 (3), 232-244.

Kurun, İ. (2019). Devrim Teorileri Işı̆̆ında 2011 Misır Devrimi ve Sonrasi: Ne Tür bir Devrim Gerçekleşti?, Ankara Üniversitesi SBF Dergisi, 74 (4), 1011-1035.

Lelandais, G. E. (2009). Sosyal Hareket Teorileri ve Küreselleşme, içinde Küreselleşme, Direniş, Ütopya -Yeni Toplumsal Hareketler - Küreselleşme Çağ̊nda Toplumsal Muhalefet, Ed.: B. Çoban,İ̀stanbul: Kalkedon Yayınlar1, 63-90.

Le Bon, G. (1977). The Crowd: A Study of the Popüler Mind, New York: Penguin Books.

Le Bon, G. (1997). Kitleler Psikolojisi, Çev.: Y. Ender, İstanbul: Hayat Yayınları.

Mermer, A (2016). Yeni Sosyal Hareketler Bağlamında Bergama Mücadelesi. Adnan Menderes Üniversitesi, Sosyal Bilimler Enstitüsü, Yüksek Lisans Tezi, Aydın (Yayımlanmamış).

MFA (2020). http://www.mfa.gov.tr/fransa-ekonomisi.tr.mfa, (24.01.2020).

Olson, M. (1965). The Logic of Collective Action: Public Goods and the Theory of Groups, Cambridge: Harvard University Press.

Olson, M. (2002). The Logic of Collective Action, Massachusetts: Harvard University Press.

Öngör, I. (2018). 2000’li Yıllarda Toplumsal Hareketler ve Sivil Toplum Tartışmaları. Hacettepe Üniversitesi Sosyal Bilimler Enstitüsü, Yüksek Lisans Tezi, Ankara (Yayımlanmamış).

Özen, H. (2015). Meydan Hareketleri ve ‘Eski’ ve 'Yeni’ Toplumsal Hareketler, Müllkiye Dergisi, 39 (2), $11-40$. 
Çapar, S., \& Koca, M. (2020). Yeni toplumsal hareketlerin farklı ülkeler üzerindeki etkileri: Tunus, Misır, Türkiye ve Fransa'dan örnekler. Journal of Human Sciences, 17(2), 642-658. doi:10.14687/jhs.v17i2.5986

Philips, K. ve K. Szagala (2007). Social Movements and News Media. The McMaster Journal of Communication, 4 (1), 39-51.

McAdam, D., Tarrow, S. ve C. Tilly (2001). Dynamics of Contention, Cambridge: Cambridge University Press.

McCarty, J. ve M. Zald (1977). Resource Mobilization and Social Movements: A Partial Theory. American Journal of Sociology, No: 82, 1212-1241.

Sınmaz, K. (2019). Misır Raporu Devrim ve Darbe Sarmalında Bir Toplum, Insamer, Araştırma 102.

Sikharulidze, L. (2019). The Anatomy of the Yellow Vest Movement, Strategic Analysis Center https://gsac.ge/wp-content/uploads/2019/04/The-Anatomy-of-the-Yellow-VestMovement.pdf, (26.09.2019).

Smelser, N. J. (1962). Theory of Collective Behavior, New York: Free Press.

Soysal, E. (2018). Toplumsal Hareket Kuramları, içinde Toplumsal Hareketler ve Kitle Psikolojisi, Ed.: C. Taştan ve E. Soysal, Ankara: Polis Akademisi Yayınları, 63-80.

Şencan, H. (2017). Catısmacı Parlamentarizmden Melez Bir Cözüume: Fransa'da Yar Başkanlı Sistemi, Karşılaştırmalu Hükü̈met Sistemleri: Yar-Baskeanllk Sistemi (Fransa, Polonya ve Rusya Örnekleri), Ankara: TBMM Araştırma Hizmetleri Başkanlığı Yayınları.

Taştan, C. (2018). Kollektif Eylemler ve Toplumsal Değişim: 2011 Arap Ayaklanmaları, içinde Toplumsal Hareketler ve Kitle Psikolojisi, Ed.: C. Taştan ve E. Soysal, Ankara: Polis Akademisi Yayınlar1, 115-146.

Telci, İ. N. (2012). Mısır 2011, Ortadoğu Yıllığ1 2011, Ankara: Açılım Kitap.

Telli, A. (2012). Misır Devrimi’nde Sosyal Medyanın Rolü. Bilge Strateji, 4 (7), 65-91.

Tiğlı, İ. (2011). Tunus'ta Halk Hareketi ve Sosyal Ağlar. Tunus: “Devrim”in Fitili, İstanbul: Dübam Yayınlar1. http://media.dunyabulteni.net/ file/2014/tunus.pdf, (15.10.2019).

Tilly, C. (2008). Toplumsal Hareketler 1768-2004, Çev.: O. Düz, İstanbul: Babil Yayınları.

Tunç, H. (2008). Demokrasi Türleri ve Müzakereci Demokrasi. Gą̧i Üniversitesi Hukuk Fakültesi Dergisi, 12 (1-2), 113-1132.

TÜİK (2018). Yıllara Göre Nüfus, http://tuik.gov.tr/UstMenu.do?metod=temelist, (07.09.2018).

Ulutaş, U. ve T. Torlak (2011). Devrimden Demokrasiye Tunus'un Seçimi. SETA Analiz, Sayı: 46, 4-24.

Ural, Ş. (1999). Demokrasi Kavram1, Toplumsal Değerler ve Birey. Ankara Üniversitesi İlabiyat Fakültesi Dergisi, 40 (1), 451-459.

Worldbank (2020). https:// data.worldbank.org/country/turkey?locale=tr, (24.01.2020).

\section{Extended English Summary}

The concept of democracy has been a controversial concept about what it is or what it is not since its emergence. Although the concept means "administration of the public" etymologically, it has gained many different meanings and contents in today's modern societies.

Democracy is defined as the "self-government of the people" in its most basic meaning. However, if it is compressed in a Socratic dialogue or discussion, the concept has undergone a change as the consent of the majority.

The history of social movements can be taken as far back as human history. With the development of democracy, the impact of social movements on political/social decision-making processes has changed significantly, especially in the $21^{\text {st }}$ century. In fact, it has started to be called as "new social movements".

An economic or social problem that emerges in a small geography in today's world can spread to different geographies very quickly owing to the effectiveness of communication capacity. Thus, it can spread to different areas by taking reference from the problem areas at the beginning and in time, it can turn into demands for political change by experiencing rapid swings. 
Çapar, S., \& Koca, M. (2020). Yeni toplumsal hareketlerin farklı ülkeler üzerindeki etkileri: Tunus, Mısır, Türkiye ve Fransa'dan örnekler. Journal of Human Sciences, 17(2), 642-658. doi:10.14687/ihs.v17i2.5986

In the context of social movements literature, it seems quite difficult to make a single definition because each social movement has very different features than others. In the simplest sense, social movements can be defined as movements that derive from the conflicts that exist between the social strata and arise as collective action.

The rise of social movements with the 1960s showed its effect in the field of academic studies and revealed two schools that have an important place today. One of them is the Resource Mobilization Theory, which is more effective in the USA; the other is the New Social Movement approach that affects Europe.

The Resource Mobilization Theory has focused on social movement organizations in relation to protest activities. New Social Movement approach, on the other hand, focuses on other factors such as political, sociological and economic resources that are important in the emergence and the development of the movement.

In addition to these theories, the Political Processes (Possibilities) Theory focuses on the relationship network that covers the political system in which they exist and their actions against it. Since the beginning of the 1980s, social psychology was again strongly included in the work, and in this process, the effects of emotions, ideas, and ideologies on social movements were reconsidered.

New Social Movements, which form the basis of this study, are more sensitive to the topics related to cultural or life styles than socioeconomic needs.

Interaction is a basic element for social movements, and communication is a basic element for interaction. In order for a social movement to emerge and influence, there is a need for constant communication between the participants in the movement, and between the movement and society.

From a social movement perspective, it is important to inform the society via the media. For this reason, the relationship with the media has a key role to announce the goals and justifications of social movements to the masses.

In addition to the traditional written and visual media, the existence of the internet and social media as an alternative media medium carries a strategic tool function for reflecting a social movement to the public and massizing the movement. In this context, it has been observed that a new type of individual has emerged within the framework of social movements after new media or social media.

Social media has contributed to forming the awareness of coming together, facilitating the physical gathering of the masses. In the postmodern times of the $21^{\text {st }}$ century, social movements led by young people have now started to focus on identity, democracy, terrorism or economic-centered issues that promises a better life.

Changes in the ways of action and differences in the type organization of new social movements compared to the past have also changed the course of demands and actions. Social movements that wanted to seize power in the past have started to bring more specific demands on the agenda, but the establishment of a democratic culture has determined the outcome of these movements.

The efforts of the new social movements to influence the political field have led to different results in different countries depending on whether the culture of democracy is established or not. The developments in Tunisia and Egypt, in which democracy is not well-established, after the Arab Spring and the developments in France and Turkey, in which democracy is well established, after Yellow Vest and Gezi Park protests can be given as examples to this case.

In this context, in Tunisia, according to some, the Jasmine Revolution, according to others, the Arab Spring, according to others, is called the Facebook revolution, and when the developments in the process from Buazizi's action until Bin Ali fled abroad, the actions, evolving to an unpredictable and unplanned point, have taken the character of an anti-government uprising in which the demand for change of management was brought to the fore. 
A similar process took place in Egypt, and anti-government demonstrations in Tunisia, that developed as a result of Muhammad Buazizi's setting himself on fire, spread to Egypt. Hüsnü Mubarak, who has been in power for nearly 30 years, had to resign 18 days after the start of the demonstrations.

The protests that took place in France, called the Yellow Vest movement, had a shock effect in the world along with the violent movements. Time and developments will determine how long the actions of the Yellow Vests will continue and in what direction they will turn.

The protests of Gezi Park in Turkey began as an environmental movement against urban renewal. In the process, although the activists made political demands, the actions ended without any change in government.

As a result, in the process that started with the Arab Spring, in countries such as Egypt and Tunisia where a democratic culture has not settled, the demands, being politicized rapidly, have caused the administrations to be overthrown or changed by coups. But in countries with a long history and culture of democracy such as Turkey and France, even though there have been demands of the change of government from the activists, the actions did not lead to a change in the government.

In this context, it can be stated that countries with a deep-rooted history of democracy and an internalized culture of democracy are more loyal to democratic principles and merits than the countries lacking this. 